\title{
Adaptation amidst Prosperity and Adversity: Insights from Happiness Studies from around the World
}

\section{Carol Graham}

Some individuals who are destitute report to be happy, while others who are very wealthy report to be miserable. There are many possible explanations for this paradox; the author focuses on the role of adaptation. Adaptation is the subject of much work in economics, but its definition is a psychological one. Adaptations are defense mechanisms; there are bad ones like paranoia, and healthy ones like humor, anticipation, and sublimation. Set point theory — which is the subject of much debate in psychology-posits that people can adapt to anything, such as bad health, divorce, and extreme poverty, and return to a natural level of cheerfulness. The author's research from around the world suggests that people are remarkably adaptable. Respondents in Afghanistan are as happy as Latin Americans and 20 percent more likely to smile in a day than Cubans. The findings suggest that while this may be a good thing from an individual psychological perspective, it may also shed insights into different development outcomes, including collective tolerance for bad equilibrium. The author provides examples from the economics, democracy, crime, corruption, and health arenas. JEL codes: I31, I32

When I sell liquor, it's called bootlegging; when my patrons serve it on Lake Shore Drive, it's called hospitality.

(Al Capone)

In the past few years there has been a burgeoning literature on the economics of happiness. While the understanding and pursuit of happiness has been a topic for philosophers - and psychologists-for decades, it is a novel one for economists. 
Early economists and philosophers, ranging from Aristotle to Bentham, Mill, and Smith, incorporated the pursuit of happiness in their work. Yet as economics grew more rigorous and quantitative, more parsimonious definitions of welfare took hold. Utility was taken to depend only on income as mediated by individual choices or preferences within a rational individual's monetary budget constraint (revealed preferences). Most economists shied away from survey data (expressed preferences), under the assumption that there is no consequence to what people say, as opposed to the concrete trade-offs that are posed by consumption choices. This focus on revealed preferences has been a powerful tool for answering many economics questions. Yet it does not do a good job of explaining a number of questions. These include the welfare effects of institutional arrangements that individuals are powerless to change; choices that are made according to perceptions of fairness or other principles; situations where individuals are constrained in their capacity to make choices; and seemingly non-rational behaviors that are explained by norms, addiction, and self-control. Happiness surveys provide us with a novel metric. Traditional approaches also do not do a good job of explaining why some individuals with very little capacity to consume are very happy, while others with a very great capacity are miserable.

In this paper I focus on the latter question and build on research that I have done on happiness across the world, in very poor and in very rich countries (Graham 2009). It departs from my earlier research (Graham 2005) on how the usage of novel metrics to assess the well-being of individuals can (or cannot) contribute to our understanding of development questions; and in this is distinct in its focus on the role of adaptation. Adaptation may shed insights on particular development outcomes, such as societies stuck in bad equilibrium, with high levels of poverty, corruption, and other negative phenomena, with most citizens reporting relatively high levels of happiness. I provide examples from countries and regions around the world - a much broader developing country representation than the previous research-and from a number of domains, including macroeconomic growth, democracy, crime, corruption, and health.

While adaptation is a topic of many economic studies, its roots are in a psychological definition. Adaptations as defined by Anna Freud are unconscious thoughts and behaviors that either shape or distort a person's reality. A simpler definition is that they are defense mechanisms. There are unhealthy ones like paranoia and megalomania, which make reality tolerable for the people enjoying them, and there are neurotic defenses employed by "normal" people, such as dissociation and memory lapse. "Healthy" or mature adaptations include altruism, humor, anticipation, and sublimation (Wolf Shenk 2009).

People can adapt to almost anything: bad health, divorce, poverty, unemployment, and high levels of crime and corruption. Indeed, some psychologists believe that individuals can adapt back from almost any negative event to their natural 
set point of cheerfulness. Adaptation is seemingly a very good thing-a human defense mechanism.

My studies of happiness around the world suggest that the human race is tremendously adaptable. People in Afghanistan, for example, are as happy as Latin Americans and are 20 percent more likely to smile in a day than are Cubans. The poor in Africa are more hopeful than the rich, and the poor in poor countries in Latin America assess their health better than the poor in rich countries in Latin America. Kenyans are more satisfied with their health systems than are Americans, and victims of crime in crime-ridden cities across the world are less happy about being crime victims than are crime victims in much safer places. What can we make of this?

In this paper, I argue that the ability to adapt is indeed a good thing from an individual happiness and psychological perspective. But this same human defense mechanism may shed insights on how some societies stay stuck in bad equilibrium — such as high levels of corruption, bad governance, or bad healthfor prolonged periods of time, while much more prosperous ones continue to go from good to better equilibrium.

\section{Happiness Economics and the Easterlin Paradox}

Richard Easterlin was the first modern economist to revisit the concept of happiness, beginning in the early 1970s. More generalized interest took hold in the 1990s, and a number of economists began to study happiness and its relationship with a number of variables of interest, including income, sociodemographic variables, employment status, the nature of political regimes, the level of economic development, and the scope and quality of public goods, among others. ${ }^{1}$

Happiness surveys are based on questions in which the individual is asked, "Generally speaking, how happy are you with your life" or "how satisfied are you with your life", with possible answers on a four to seven point scale. Answers to happiness and life satisfaction questions correlate quite closely. ${ }^{2}$ Still, the particular kind of happiness question that is used matters to the results. For example, respondents' income level seems to matter more to their answers to lifesatisfaction questions than it does to their answers to questions which are designed to gauge the innate character component of happiness (affect), as gauged by questions such as "How many times did you smile yesterday?"

Happiness questions are also particularly vulnerable to order bias. People will respond differently to an open-ended happiness question that is in the beginning of a survey than to one that is framed or biased by the questions posed beforehand, such as those about whether income is sufficient or the quality of their job. 
Bias in answers to happiness surveys can also result from unobserved personality traits. A naturally curmudgeonly person, for example, will answer all sorts of questions in a manner that is more negative than the average. (These concerns can be addressed via econometric techniques if and when we have panel data.) Related concerns about unobservable variables are common to all economic disciplines and are not unique to the study of happiness. For example, a naturally cheerful person may respond to policy measures differently, put more effort in the labor market than the average, or both.

Despite the potential pitfalls, cross-sections of large samples across countries and over time find remarkably consistent patterns in the determinants of happiness. Psychologists, meanwhile, find validation in the way that people answer these surveys according to physiological measures of happiness, such as the frontal movements in the brain and in the number of "genuine"-Duchennesmiles (Diener and Seligman (2004).

The data in happiness surveys are analyzed via standard econometric techniques, with an error term that captures the unobserved characteristics and errors described above. ${ }^{3}$ Because the answers to happiness surveys are ordinal rather than cardinal, they are best analyzed via ordered logistic or probability (probit) equations. These equations depart from standard regression equations, which explore a continuous relationship between variables (for example happiness and income), and instead explore the probability that an individual will place him or herself in a particular category, typically ranging from unhappy to very happy. These regressions usually yield lower R-squares than economists are used to, reflecting the extent to which emotions and other components of true well-being are driving the results, as opposed to the variables that we are able to measure, such as income, education, and employment status.

While it is impossible to measure the precise effects of independent variables on true well-being, happiness researchers have used the coefficients on these variables as a basis for assigning relative weights to them. ${ }^{4}$ For example, they have estimated how much income a typical individual in the United States or Britain would need to produce the same change in stated happiness that comes from the well-being loss resulting from, for example, divorce $(\$ 100,000)$ or job loss (\$60,000) (Blanchflower and Oswald 2004). Because of the low R-squares in these equations, as so much of happiness is explained by individual-specific character traits, these figures should be interpreted in relative terms-for example how much the average individual values employment relative to stable marriage - rather than as precise estimates of willingness to pay.

In his original study, Easterlin revealed a paradox that sparked interest in the topic, but this is as yet unresolved. While most happiness studies find that within countries wealthier people are, on average, happier than poor ones, studies across countries and over time find very little, if any, relationship between increases in 
per capita income and average happiness levels. On average, wealthier countries (as a group) are happier than poor ones (as a group); happiness seems to rise with income up to a point, but not beyond it. Yet even among the less happy, poorer countries, there is not a clear relationship between average income and average happiness levels, suggesting that many other factors-including cultural traits-are at play.

More recently, there has been renewed debate over whether there is an Easterlin paradox or not. ${ }^{5}$ Why the discrepancy? For a number of reasons-many of them methodological-the divergent conclusions may each be correct. The relationship between happiness and income is mediated by a range of factors that can alter its slope, functional form, or both. These include the particular questions that are used to measure happiness, the selection of countries that is included in the survey sample, the specification of the income variable (log or linear), the rate of change in economic conditions in addition to absolute levels, and changing aspirations as countries go from the ranks of developing to developed economies. $^{6}$

There is much less debate about the relationship between income and happiness within countries. Income matters to happiness (Oswald 1997; Diener and others 1993). Deprivation and abject poverty in particular are very bad for happiness. Yet after basic needs are met other factors such as rising aspirations, relative income differences, and the security of gains become increasingly important, in addition to income. ${ }^{7}$ A common interpretation of the Easterlin paradox is that humans are on a "hedonic treadmill": aspirations increase along with income and, after basic needs are met, relative rather than absolute levels of income matter to well-being. Another interpretation of the paradox is the psychologists' "set point" theory of happiness, in which every individual is presumed to have a happiness level that he or she goes back to over time, even after major events such as winning the lottery or getting divorced (Easterlin 2003). The implication of this theory for policy is that nothing much can be done to increase happiness.

There is no consensus about which interpretation is most accurate. Even if levels eventually adapt upwards to a longer-term equilibrium, mitigating or preventing the unhappiness and disruption that individuals experience in the interim certainly seems a worthwhile objective. Set point theory, meanwhile, does not tell us much about the welfare implications of adaptation. In this paper I address the latter question and examine how and under what conditions individuals adapt to both good and bad phenomena, such as wealth, freedom, crime and corruption, and ill health, among other things. A look across substantive domains suggests a remarkable human capacity to cope with adversity. A look across countries suggests that this same capacity may help explain how societies get stuck in outcomes which are bad for aggregate welfare. 


\section{Unhappy Growth, Frustrated Achievers, Crises, and More}

We know that within societies wealthier people are happier than the average, but after that the income-happiness relationship becomes more complicated. At the macroeconomic level, the relationship between happiness and income may be affected as much by the pace and nature of income change as it is by absolute levels. Both the behavioral economics and happiness literature highlight the extent to which individuals adapt very quickly to income gains and disproportionately value income losses.

Based on the Gallup World Poll in 122 countries around the world, Eduardo Lora and collaborators find that countries with higher levels of per capita GDP have, on average, higher levels of happiness. Yet controlling for levels, they find that individuals in countries with positive growth rates have lower happiness levels. When they split the sample into above and below median growth rates, the unhappy growth effect only holds for those that are growing at rates above the median (table 1). In related work, Lora and I chose to call this negative correlation between economic growth and happiness the "paradox of unhappy growth". ${ }^{8}$

Deaton, and Stevenson and Wolfers, also find evidence of an unhappy growth effect based on the Gallup World Poll. Stevenson and Wolfers find insignificant effects of growth in general, but strong negative effects for the first stages of growth in "miracle" growth economies, such as Ireland and South Korea during their take-off stages. The negative effect becomes insignificant in later stages (Deaton 2008; Stevenson and Wolfers 2008). Deaton finds that the inclusion of region dummies makes a major difference to the results, with the significance

Table 1. The Paradox of Unhappy Growth: The Relationship among Satisfaction, Income Per Capita, and Economic Growth, 122 Countries

\begin{tabular}{lcl}
\hline Dependent variable & GDP per capita & Economic growth \\
\hline Life satisfaction & $0.788^{* * *}$ & $-0.082^{* * *}$ \\
Standard of living & $0.108^{* * *}$ & $-0.018^{* * *}$ \\
Health satisfaction & $0.017^{*}$ & $-0.017^{* * *}$ \\
Job satisfaction & $0.077^{* * *}$ & -0.006 \\
Housing satisfaction & $0.084^{* * *}$ & -0.006 \\
\hline
\end{tabular}

Notes: OLS regression; dependent variable is average life satisfaction per country, growth rates are averaged over the past five years. $N=122$. The coefficients on GDP per capita are marginal effects; how much does the satisfaction of two countries differ when one has two times the incomes of another. The coefficients on growth imply how much an additional percentage point of growth affects life satisfaction. The life satisfaction variable is on a 0 to 10 scale; all others are the percentage of respondents that are satisfied.

Source: Eduardo Lora. "Beyond Facts: Understanding Quality of Life in Latin America and the Caribbean". Inter-American Development Bank using Gallup World Poll 2006 and 2007. 
being taken up by Africa and Russia, regions which were both fast growing at the time. It is important to distinguish between levels and change effects here, as happiness levels in Russia are lower than their income levels would predict, while in some-but not all-African countries, such as Nigeria, levels are higher than income levels would predict. Both seem to be unusually unhappy at times of rapid growth, for any number of plausible reasons. It is also possible that the unhappiness started before the growth and not after it.

Soumya Chattopadhyay and I, using Latinobarometro data, also find hints of an unhappy growth effect, or at least an irrelevant growth effect. In contrast to the above studies, we use individual rather than average country happiness on the left-hand side, with the usual sociodemographic and economic controls and clustering the standard errors at the country level. When we include the current GDP growth rate in the equation, as well as the lagged growth rate from the previous year (controlling for levels), we find that the effects of growth rates-and lagged growth rates - are, for the most part, negative but insignificant (table 2) (Graham and Chattopadhyay 2008a).

There are a number of explanations for these findings, including the insecurity that is attached to rapidly changing rewards structures and macroeconomic volatility, and the frustration that rapidly increasing inequality tends to generate. They surely highlight how individuals are better able to adapt to the gains that accompany rapid growth than to the potential losses and uncertainty that are also associated with it. They also suggest that individuals are often more content in low growth equilibrium than in a process of change which results in gains but instability and unequal rewards at the same time.

The within-country income and happiness story is also more complicated than the averages suggest. It is typically not the poorest people that are most frustrated or unhappy with their conditions or the services that they have access to. Stefano Pettinato and I, based on research in Peru and Russia, identified a phenomenon that is now termed the "happy peasant and frustrated achiever" problem (see Graham and Pettinato 2002). This is an apparent paradox, where very poor and destitute respondents report high or relatively high levels of well-being, while much wealthier ones with more mobility and opportunities report much greater frustration with their economic and other situations. This may be because the poor respondents have a higher natural level of cheerfulness or because they have adapted their expectations downwards. The upwardly mobile respondents, meanwhile, have constantly rising expectations (or are naturally more curmudgeonlike). ${ }^{9}$ And a third explanation is also possible: that more driven and frustrated people are more likely to seek to escape situations of static poverty (via channels such as migration), but even when they achieve a better situation, they remain more driven and frustrated than the average. Some combination of all three explanations could indeed be at play. 
Table 2. Is Happiness Immune to Country Level Economic Growth? Dependent Variable:

Happiness

\begin{tabular}{|c|c|c|c|c|}
\hline age & $\begin{array}{c}-\mathbf{0 . 0 2 4 0} \\
(4.40)^{* *}\end{array}$ & $\begin{array}{c}-\mathbf{0 . 0 2 3 0} \\
(4.34)^{* *}\end{array}$ & $\begin{array}{c}-\mathbf{0 . 0 2 3 0} \\
(4.23)^{* *}\end{array}$ & $\begin{array}{r}-\mathbf{0 . 0 2 2 0} \\
(4.29)^{* *}\end{array}$ \\
\hline \multirow[t]{2}{*}{ age 2} & 0.0000 & 0.0000 & 0.0000 & 0.0000 \\
\hline & $(3.53)^{* * *}$ & $(3.88)^{* *}$ & $(3.72)^{* *}$ & $(3.76)^{* *}$ \\
\hline \multirow[t]{2}{*}{ gender } & 0.0330 & 0.0070 & 0.0070 & 0.0070 \\
\hline & -1.5500 & -0.4800 & -0.5200 & -0.4800 \\
\hline \multirow[t]{2}{*}{ married } & 0.0790 & 0.0910 & 0.0940 & 0.0930 \\
\hline & -1.7800 & $(2.40)^{*}$ & $(2.56)^{*}$ & $(2.60)^{* *}$ \\
\hline \multirow[t]{2}{*}{ edu } & -0.0410 & -0.0260 & -0.0280 & -0.0260 \\
\hline & -1.5300 & -1.1800 & -1.2900 & -1.2800 \\
\hline \multirow[t]{2}{*}{ edu2 } & 0.0010 & 0.0010 & 0.0010 & 0.0010 \\
\hline & -0.8800 & -0.7000 & -0.7900 & -0.7600 \\
\hline \multirow[t]{2}{*}{ socecon } & 0.2110 & 0.2160 & 0.2150 & 0.2170 \\
\hline & $(5.22)^{* *}$ & $(5.76)^{* *}$ & $(5.77)^{* *}$ & $(5.78)^{* *}$ \\
\hline \multirow[t]{2}{*}{ subinc } & 0.2900 & 0.2900 & 0.2940 & 0.2920 \\
\hline & $(8.78)^{* *}$ & $(8.02)^{* *}$ & $(8.36)^{* *}$ & $(8.41)^{* *}$ \\
\hline \multirow[t]{2}{*}{ ceconcur } & 0.2340 & 0.2260 & 0.2360 & 0.2370 \\
\hline & $(9.04)^{* *}$ & $(9.50)^{* *}$ & $(7.66)^{* *}$ & $(8.92)^{* *}$ \\
\hline \multirow[t]{2}{*}{ unemp } & -0.1810 & -0.1760 & -0.1900 & -0.1880 \\
\hline & $(2.05)^{*}$ & $(3.45)^{* *}$ & $(3.59)^{* *}$ & $(3.69)^{* *}$ \\
\hline \multirow[t]{2}{*}{ poum } & 0.1800 & 0.1890 & 0.1830 & 0.1840 \\
\hline & $(4.48)^{* *}$ & $(5.42)^{* *}$ & $(5.56)^{* *}$ & $(5.59)^{* *}$ \\
\hline \multirow[t]{2}{*}{ domlang } & 0.5380 & 0.4810 & 0.4840 & 0.4810 \\
\hline & $(2.73)^{* *}$ & $(2.48)^{*}$ & $(2.48)^{*}$ & $(2.48)^{*}$ \\
\hline \multirow[t]{2}{*}{ vcrime } & -0.1160 & -0.1060 & -0.1060 & -0.1080 \\
\hline & $(2.30)^{*}$ & $(2.98)^{* *}$ & $(2.89)^{* *}$ & $(3.08)^{* *}$ \\
\hline \multirow[t]{2}{*}{ els } & 0.0900 & & & \\
\hline & $(5.48)^{* *}$ & & & \\
\hline \multirow[t]{2}{*}{ growth_gdp } & 0.0170 & -0.0090 & -0.0040 & -0.0060 \\
\hline & -0.5300 & -1.1100 & -0.6000 & -0.7700 \\
\hline \multirow[t]{2}{*}{ gini } & -0.0170 & -0.0270 & -0.0240 & -0.0240 \\
\hline & -0.7000 & -1.2400 & -1.1200 & -1.1900 \\
\hline \multirow[t]{2}{*}{ gdpgrl1 } & & & -0.0190 & -0.0180 \\
\hline & & & -1.4000 & -0.9900 \\
\hline \multirow[t]{2}{*}{ gdpvol2 } & & & & 0.0030 \\
\hline & & & & -0.1400 \\
\hline Observations & 34808 & 67308 & 67308 & 67308 \\
\hline \multirow{2}{*}{\multicolumn{5}{|c|}{ Absolute value of $\mathrm{z}$ statistics in parentheses. }} \\
\hline \multicolumn{4}{|c|}{$*$ significant at $5 \%$;* significant at $1 \%$} & \\
\hline \multicolumn{5}{|c|}{ Regressions clustered at a country level. } \\
\hline Source: Grahar & topadhyay $(2$ & & & \\
\hline
\end{tabular}


The poor, some of whom rely on subsistence agriculture rather than earnings, have little to lose and have likely adapted to constant insecurity. Recent research on job insecurity shows that reported insecurity is actually higher among formal sector workers with more stable jobs than it is among informal sector workers. The latter have adapted to higher levels of income and employment insecurity, have selected into jobs with less stability but more freedom, or both (Graham and Lora 2009).

Other studies find an analogous urban effect in China, where urban migrants are materially better off than they were in their premigration stage, yet report higher levels of frustration with their material situation. Their reference norm quickly shifted to other urban residents rather than their previous peers in rural areas (Knight and Gunatilaka 2007; Whyte and Hun 2006).

Individuals seem to adapt much more to income gains than to status gains (Tella and MacCulloch 2006). In the context of the frustrated achievers in very volatile emerging market contexts, where currencies are often shifting in value and where the rewards to particular skill and education sets are in flux, as are social welfare systems, income gains may seem particularly ephemeral. ${ }^{10}$

Crises bring about both significant losses and uncertainty. Not surprisingly, they bring movements in happiness of an unusual magnitude. While national average happiness levels do not move much, they surely do at times of crisis, although they eventually adapt back. Our research on crises in Russia, Argentina, and the United States suggests that the unhappiness effects of crises are as much due to the uncertainty they generate as they are to the actual drops in income levels that they cause (as people have a much harder time adapting to uncertainty than to one-time shocks). ${ }^{11}$

\section{Adapting to Good and Bad Fortune: How Friends, Freedom, Crime, and Corruption affect Happiness}

We have seen that rapid economic growth can cause unhappiness and that people adapt very quickly to the gains that growth brings about. What about other factors that affect well-being, such as religion, friendships, personal liberty, participating in politics, and criminal violence? One can imagine average happiness levels being pulled down in a relatively wealthy country which has high levels of crime. Or, in contrast, happiness being higher than predicted by per capita income levels in a poor country with very strong social capital. And it is not clear that crime rates or social capital have the same effects on well-being in every context.

\section{Social Capital and Friendships}

There is a wide literature - pioneered by Robert Putnam —on the importance of social capital to a host of outcomes ranging from economic development to 
democratic government to health. There is a wide body of empirical evidence linking higher levels of social capital to outcomes that are, on balance, positive for quality of life and economic progress, such as economic growth, better governance, and higher levels of productivity. ${ }^{12}$ Not surprisingly, there are also positive links between well-being and friendships, narrowly defined, and social capital, more broadly defined. What is harder to disentangle, though, is whether happier people make more friends, interact with others more, or both, or whether friendships and social interactions make people happier.

Eduardo Lora and I and a team of colleagues at the Inter-American Development Bank evaluated the importance of friendships. The Gallup World Poll has a variable which asks the respondent whether or not he or she has friends or relatives who can be counted on. ${ }^{13}$ Friendships and relatives matter more to the well-being of the average Latin American respondent than health, employment, or personal assets, and only slightly less than food security (of course it could be that happier people are more likely to have and value friendships). This varies according to income levels, with the rich valuing work and health more, and the poor valuing friendships (see figure 1).

Figure 1. Monetary Valuation of Some Life-satisfaction Determinants: Income Required to Compensate a Person for the Effects Related to a Change in Life Conditions

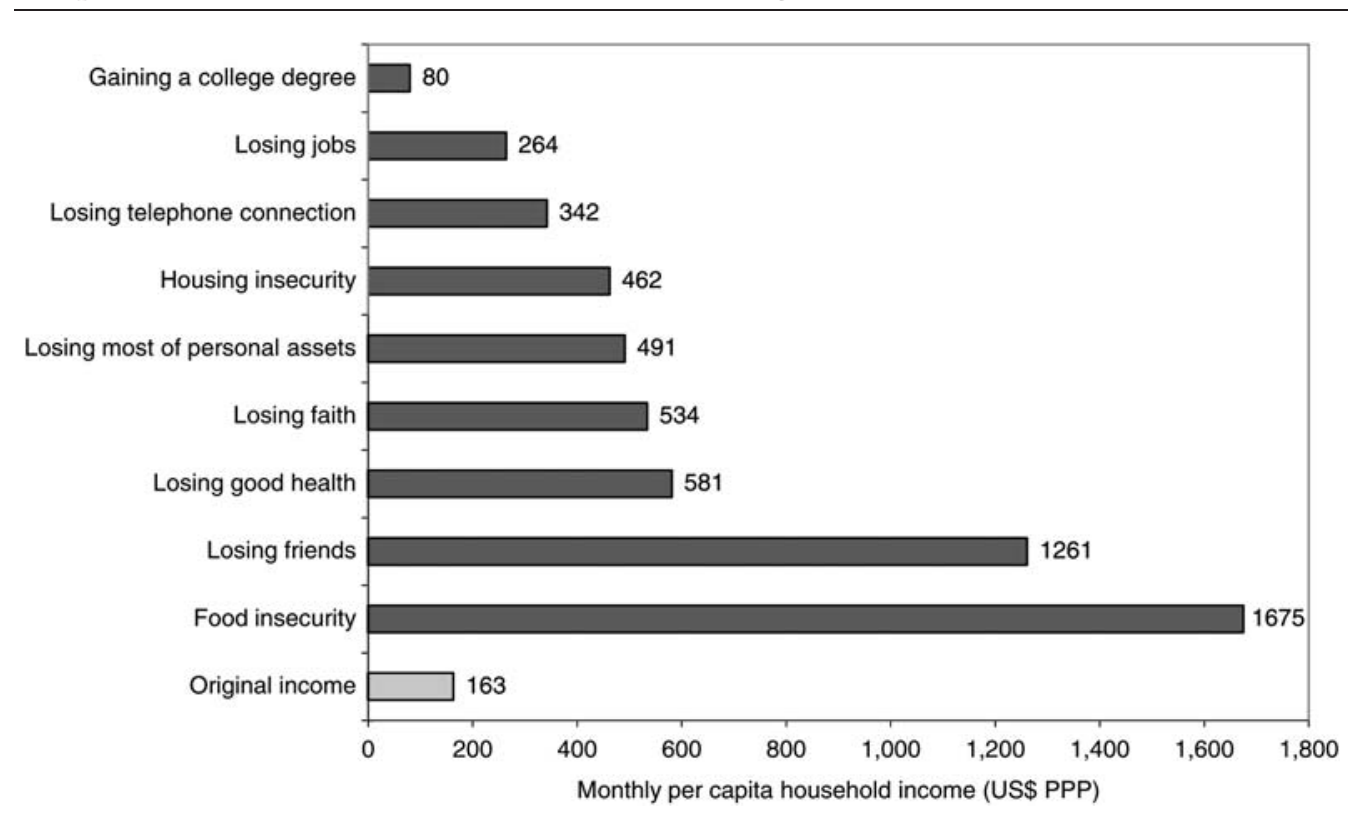

Note: The base comparison case is a single 30-year-old woman, with no children, a high-school degree, employed, has friends and religious beliefs.

Source: Inter-American Development Bank (2008). 
These friendships most likely provide important coping mechanisms for the poor in the absence of publicly provided safety nets. Whether they serve as strong or weak ties in the Granovetter sense is an open question (Granovetter 1973). Reporting religion to be important and having access to a telephone, meanwhile, are also positively correlated with happiness in the region. Both variables likely facilitate social connections and networks, among other things. ${ }^{14}$

John Helliwell has done extensive research into whether living in contexts with greater social capital and with greater freedom play a role in individual wellbeing. The basic answer is a resounding yes on both fronts. In his most recent paper, based on the Gallup World Poll, Helliwell and colleagues compare the various determinants of well-being across 120 countries in the five regions covered by the Poll. ${ }^{15}$ They find that all measures of social connections are significantly correlated with life satisfaction across the countries and regions in the sample. Respondents seem to value both the support that they get from others and the support that they give to others.

Other studies-including our own-find that having trust in others in general is linked to higher levels of well-being. Of course, the usual problem of not being able to disentangle whether happier people are more likely to have trust, or whether trusting others per se generates happiness, applies. In addition, this relationship between trust and higher levels of well-being is likely stronger in contexts where trusting public institutions is the norm rather than an aberration.

An example of the latter is Afghanistan, where we have most recently studied happiness. Low levels of trust in public institutions and interpersonal trust coexist with relatively high levels of reported happiness as well as measures of affect, such as frequency of smiling yesterday (with average happiness and affect levels above the world average and equivalent to the Latin American regional average). Most people were more likely to trust those in their neighborhood than to trust others more generally. After years of warfare and turmoil, low levels of general trust are not a surprise. At the same time, the majority of respondents seem to be able to maintain their general or natural cheerfulness despite that adversity and lack of generalized trust. ${ }^{16}$

\section{Political Freedom, Political Participation, and Happiness}

There is substantial work on the effects of political participation-and the nature of government regimes - on happiness. The channels through which these factors operate, however, are not completely clear. One can imagine that the nature of political regimes matter to people's well-being and that living with freedom and good government is better than not. In his world-wide Gallup Poll study, Helliwell finds that citizens that live in a context of freedom are significantly happier than those that do not. And, as is suggested above, freedom seems to matter more to 
the happiness of those that have come to expect it than to those that do not (Helliwell, Haifang Huang, and Harris 2008; see also Hudson 2006; Veenhovern 2000; Frey and Stutzer 2002).

Stefano Pettinato and I, using Latinobarometro data, found that individual respondents' attitudes about the market and about democracy were positively correlated with happiness in Latin America. ${ }^{17}$ In other words, controlling for other variables such as income and age and using country dummies, individuals with pro-market attitudes were, on average, happier than those who did not favor market policies. Not surprisingly, wealth levels and education levels had positive and significant effects on pro-market attitudes (table 3). We also found that happier people were more likely to be pro-market, so we have the usual problem of establishing the direction of causality. It may well be that happier individuals

Table 3. Correlates of Pro-market Attitudes; Dependent Variable: Happiness

\begin{tabular}{|c|c|c|c|c|}
\hline \multirow[b]{2}{*}{ Independent variable } & \multicolumn{2}{|c|}{ (1) } & \multicolumn{2}{|c|}{ (2) } \\
\hline & Coeff. & $z$-stat & Coeff. & z-stat \\
\hline Age & -0.014 & -1.99 & -0.008 & -1.24 \\
\hline $\mathrm{Age}^{2} / 100$ & 0.011 & 1.46 & 0.001 & 0.13 \\
\hline Male & 0.050 & 1.29 & 0.036 & 0.92 \\
\hline Log(Wealth) & 0.361 & 8.08 & 0.632 & 15.11 \\
\hline Education & 0.005 & 1.01 & -0.031 & -6.34 \\
\hline Married & 0.091 & 2.30 & 0.054 & 1.35 \\
\hline \multicolumn{5}{|l|}{ Employment status } \\
\hline Self-employed & -0.083 & -1.50 & -0.110 & -1.98 \\
\hline Public employee & -0.041 & -0.53 & 0.035 & 0.45 \\
\hline Private employee & 0.000 & 0.00 & 0.026 & 0.42 \\
\hline Unemployed & -0.310 & -3.81 & -0.294 & -3.63 \\
\hline Retired & -0.082 & -0.88 & -0.030 & -0.33 \\
\hline Student & 0.091 & 1.22 & 0.049 & 0.66 \\
\hline Pro-democracy dummy & -0.017 & -0.48 & -0.132 & -3.63 \\
\hline Satisfaction with democracy & 0.307 & 14.68 & 0.362 & 18.28 \\
\hline Pro-market attitudes & 0.543 & 7.85 & 0.521 & 7.70 \\
\hline Inflation rate & & & -0.007 & -4.96 \\
\hline Unemployment rate & & & -0.004 & -0.75 \\
\hline Psuedo $R^{2}$ & \multicolumn{2}{|c|}{0.058} & \multicolumn{2}{|c|}{0.027} \\
\hline Number of observations & \multicolumn{2}{|c|}{14,255} & \multicolumn{2}{|c|}{11,197} \\
\hline
\end{tabular}

Notes: Country fixed-effects estimation.

Ordered logit estimations:

With country dummies in (1) (country coefficients not shown).

Without country dummies in (2).

Omitted reference category is housewives or househusbands.

Source: Authors' calculations using data from Latinobarometro. 
are more likely to cast whatever policy environment they inhabit in a favorable light, adapt to a range of policy environments, or both.

We also looked at Russia. As in Latin America, having a pro-market attitude had positive and significant effects on happiness in that country, suggesting that people in both regions who favor the ongoing turn to the market are in general more satisfied. Not surprisingly, having a pro-market attitude had significant and negative effects on the likelihood of respondents supporting redistribution, as did having positive prospects for the future. Information about democratic attitudes in Russia was not comparable to that in the Latinobarometro, and was based on a question asking whether respondents want to return to pre-Gorbachev (preperestroika) times. We included this question in some of our regressions as a (crude) proxy indicator of respondents' preference for democracy over communism. We found that not wanting to return to communism, like having a pro-market attitude, had a positive and significant correlation with happiness. Again the direction of causality is not clear, and it may well be that happy people are supportive of or more likely to adapt to-whatever policy environment they live in.

\section{Adapting to Freedom and Friendships?}

Helliwell and colleagues test for inter-regional differences on the effects of income, freedom, social connections - as measured by the importance of friendships and memberships in associations, among others-and corruption on well-being. They find that the income coefficient is weakest in Africa-probably due to the likelihood of mismeasurement of the income variable and the importance of subsistence agriculture. The effects of social connections are lower in Asia and Africa and higher in Region 1 (the United States, Western Europe, Australia, and New Zealand) than in any other region. The negative effects of corruption are weakest in Asia and Africa and strongest in Region 1, as are the positive effects of personal freedom.

The well-being effects of corruption seem to be lower for those living in countries where corruption is a long established feature of the status quo-and therefore people have become accustomed to it - while the well-being value attached to a sense of personal freedom is higher in societies classified as individualistic rather than collectivist. A recent paper by Ronald Inglehart and colleagues also finds that the well-being effects of freedom are greater in countries that have more of it and are more accustomed to it (Inglehart and others 2008).

\section{Adapting to Bad Equilibrium: Crime and Corruption}

Along the same vein, Soumya Chattopadhyay and I examined the extent to which individuals adapt to and become more tolerant of high levels of crime and illicit 
activity (corruption). Our initial assumption is simply described by the following vignette, based on my own experience. I grew up in Peru but live in Washington, DC. In Lima, I think nothing of removing my jewelry before going out on the street or of putting my briefcase on the floor of my car so that my windows do not get smashed as I drive. In contrast, I would be outraged if I had to take similar precautionary measures when I step out of my Dupont Circle office.

We used our pooled Latinobarometro data to test the extent to which the wellbeing effects of being a crime victim are lower-as are reporting rates-in countries in Latin America where crime rates are higher. As crime rates go up, citizens typically adapt, which is evidenced in lower reporting rates (reporting of petty crimes is less likely to result in corrective action as overall rates go up) and less stigma attached to being a victim. Nick Powdthavee's work on crime in South Africa suggests similar dynamics. ${ }^{18}$

If higher levels of crime and corruption are the norm, and individuals adapt to those norms and come to expect high levels of crime and corruption, as in Latin America, then it may be more difficult to generate the social and political support that is necessary for the difficult policy measures required to achieve a lower crime norm. We took advantage of the variance in levels of crime and corruption across Latin American countries as a means to test this proposition. We posit that understanding the important role of norms in individuals' responses to legal and institutional changes is likely an important part of the design of policies to reverse crime and corruption.

Several papers have documented the well-being costs associated with being a victim of crime or corruption. We build from the assumption that these phenomena are negative for individual welfare and explore the extent to which the costs are mediated by norms of behavior and by adaptation. Are the well-being costs of being a (petty) crime victim or of having to pay a bribe lower in contexts where these phenomena are more common?

On the one hand, if crime and corruption are the norm, then individuals would feel less stigmatized if they were the victim of petty crime and would feel less unethical if they had to engage in corruption to get things done. On the other hand, if crime and corruption are the norm, it is likely that individuals adapt to these phenomena, as well as to the associated costs, as common occurrences. So while individuals who live in countries where crime and corruption levels are high are likely to be less happy in general, there is less likelihood that they will be made unhappy specifically because of these phenomena.

We tested these assumptions econometrically based on several years (19982008) of pooled Latinobarometro data-which provides us with information on crime and corruption victimization (self-reported) across and within countries, and over time in aggregate levels. Our approach entailed determining the likelihood that an individual would be a crime victim, based on the usual explanatory 
factors, such as his or her own socioeconomic profile, plus the crime rate in the country that he or she lived in, plus whether or not he or she lived in a big city, and so on. We then isolated an "unexplained" victimization probability, or the victimization that we were not able to explain with the above factors, and used that probability as a proxy for differences in crime norms across respondents. ${ }^{19}$ Our intuition was that being a crime victim will have negative effects on happiness in any event, but that they will be lower when the unexplained victimization probability is higher.

Our regressions had several specifications. The first simply explored the effects of crime victimization. The second included our crime residual to see if the latter mitigated the effects of the former. In another specification, we included lagged crime victimization to see if people adapted to the effects of being a victim over time. Finally we ran a separate equation using the Economic Ladder Scale question (ELS) (where people place themselves on a societal economic ladder), which is a proxy for relative economic status; we included it in a separate specification because it was only asked in a few of the years and therefore reduces our sample size.

Our results support our intuition about unexplained crime probability. First of all, our first stage regressions yielded (expectedly) that those individuals that are older, more educated, wealthier, unemployed, speak the dominant language (that is are non-minorities), and live in a country with a higher crime rate, as well as those that were victimized in the past year, were more likely to be crime victims in the present year. In the second stage, we found that, as expected, controlling for everything else, being victimized in the past year has a negative effect on happiness today. However, having a higher crime norm (or "unexplained" victimization probability) is positively correlated with happiness, for example it acts to counter or mitigate the negative effects of victimization (table 4). Of course it is possible that our "crime norm" variable is picking up other traits that affect well being but that we cannot observe.

In our study on optimism in Africa, Matthew Hoover and I examined the extent to which optimism mediated adversity such as crime victimization. We found similar evidence of downward adaptation. Optimism or positive attitudes presumably affect the way in which people deal with adversity. We examined the wellbeing costs of having been a crime victim. We split the sample into those respondents who reported high levels of personal security and those who reported low levels, with respondents' assessments of their living conditions as the dependent variable. We then compared the coefficients on being a crime victim. We found that the costs were lower for those respondents who responded that they had high levels of insecurity than for those respondents who had low levels of insecurity (table 5).

There are several plausible explanations for this. If you expect that you will be a crime victim, some of those costs are already internalized in the expectation, and the actual event has less effects on well-being. Alternatively being a victim of 
Table 4. Effects of Crime on Happiness in Latin America, Dependent Variable: Happiness

\begin{tabular}{|c|c|c|c|c|}
\hline \multirow{2}{*}{$\begin{array}{l}\text { Explanatory variables } \\
\text { age }\end{array}$} & \multirow{2}{*}{$\begin{array}{c}\text { Base specification } \\
\mathbf{- 0 . 0 2 3 0} \\
(0.000)^{* * *}\end{array}$} & \multicolumn{3}{|c|}{ With crime residuals } \\
\hline & & $\begin{array}{c}-\mathbf{0 . 0 2 0 0} \\
(0.000)^{* * * *}\end{array}$ & $\begin{array}{l}-\mathbf{0 . 0 2 1 0} \\
(0.000)^{* * *}\end{array}$ & $\begin{array}{c}-\mathbf{0 . 0 1 8 0} \\
(0.005)^{* * *}\end{array}$ \\
\hline age 2 & $\begin{array}{l}\mathbf{0 . 0 0 0 0} \\
(0.000)^{* * *}\end{array}$ & $\begin{array}{l}\mathbf{0 . 0 0 0 0} \\
(0.000)^{* * *}\end{array}$ & $\begin{array}{c}\mathbf{0 . 0 0 0 0} \\
(0.000)^{* * *}\end{array}$ & $\begin{array}{l}\mathbf{0 . 0 0 0 0} \\
-0.051\end{array}$ \\
\hline gender & $\begin{array}{l}\mathbf{0 . 0 0 7 0} \\
-0.614\end{array}$ & $\begin{array}{l}\mathbf{0 . 0 2 1 0} \\
-0.201\end{array}$ & $\begin{array}{c}\mathbf{0 . 0 4 0 0} \\
(0.050)^{* *}\end{array}$ & $\begin{array}{l}\mathbf{0 . 0 2 4 0} \\
-0.199\end{array}$ \\
\hline married & $\begin{array}{c}\mathbf{0 . 0 8 5 0} \\
(0.000)^{* * *}\end{array}$ & $\begin{array}{l}\mathbf{0 . 0 6 0 0} \\
(0.001)^{* * *}\end{array}$ & $\begin{array}{l}\mathbf{0 . 0 6 3 0} \\
(0.004)^{* * *}\end{array}$ & $\begin{array}{l}\mathbf{0 . 0 6 2 0} \\
-0.104\end{array}$ \\
\hline edu & $\begin{array}{c}-\mathbf{0 . 0 2 2 0} \\
(0.000)^{* * *}\end{array}$ & $\begin{array}{c}-\mathbf{0 . 0 2 6 0} \\
(0.000)^{* * * *}\end{array}$ & $\begin{array}{c}-\mathbf{0 . 0 2 8 0} \\
(0.000)^{* * *}\end{array}$ & $\begin{array}{l}-\mathbf{0 . 0 2 4 0} \\
-0.385\end{array}$ \\
\hline edu2 & $\begin{array}{l}\mathbf{0 . 0 0 1 0} \\
-0.077\end{array}$ & $\begin{array}{l}\mathbf{0 . 0 0 1 0} \\
(0.038)^{* *}\end{array}$ & $\begin{array}{l}\mathbf{0 . 0 0 1 0} \\
(0.024)^{* *}\end{array}$ & $\begin{array}{c}\mathbf{0 . 0 0 1 0} \\
-0.451\end{array}$ \\
\hline socecon & $\begin{array}{l}0.2110 \\
(0.000)^{* * * *}\end{array}$ & $\begin{array}{l}\mathbf{0 . 2 1 4 0} \\
(0.000)^{* * * *}\end{array}$ & $\begin{array}{c}\mathbf{0 . 2 2 8 0} \\
(0.000)^{* * *}\end{array}$ & $\begin{array}{c}\mathbf{0 . 2 2 8 0} \\
(0.000)^{* * *}\end{array}$ \\
\hline subinc & $\begin{array}{c}\mathbf{0 . 2 8 7 0} \\
(0.000)^{* * *}\end{array}$ & $\begin{array}{l}\mathbf{0 . 3 0 3 0} \\
(0.000)^{* * * *}\end{array}$ & $\begin{array}{c}\mathbf{0 . 3 0 6 0} \\
(0.000)^{* * * *}\end{array}$ & $\begin{array}{c}\mathbf{0 . 3 1 4 0} \\
(0.000)^{* * *}\end{array}$ \\
\hline ceconcur & $\begin{array}{l}\mathbf{0 . 2 1 9 0} \\
(0.000)^{* * *}\end{array}$ & $\begin{array}{l}\mathbf{0 . 1 9 7 0} \\
(0.000)^{* * *}\end{array}$ & $\begin{array}{c}\mathbf{0 . 2 3 5 0} \\
(0.000)^{* * *}\end{array}$ & $\begin{array}{c}\mathbf{0 . 2 1 8 0} \\
(0.000)^{* * *}\end{array}$ \\
\hline unemp & $\begin{array}{c}-\mathbf{0 . 1 7 7 0} \\
(0.000)^{* * *}\end{array}$ & $\begin{array}{c}-\mathbf{0 . 2 1 7 0} \\
(0.000)^{* * * *}\end{array}$ & $\begin{array}{c}-\mathbf{0 . 1 9 9 0} \\
(0.000)^{* * *}\end{array}$ & $\begin{array}{c}-\mathbf{0 . 2 3 0 0} \\
(0.002)^{* * *}\end{array}$ \\
\hline poum & $\begin{array}{l}\mathbf{0 . 1 7 5 0} \\
(0.000)^{* * *}\end{array}$ & $\begin{array}{l}\mathbf{0 . 1 4 1 0} \\
(0.000)^{* * *}\end{array}$ & $\begin{array}{l}\mathbf{0 . 1 4 7 0} \\
(0.000)^{* * *}\end{array}$ & $\begin{array}{c}\mathbf{0 . 1 5 3 0} \\
(0.000)^{* * *}\end{array}$ \\
\hline domlang & $\begin{array}{l}\mathbf{0 . 5 9 5 0} \\
(0.000)^{* * *}\end{array}$ & $\begin{array}{l}\mathbf{0 . 6 5 2 0} \\
(0.000)^{* * *}\end{array}$ & $\begin{array}{l}\mathbf{0 . 6 3 6 0} \\
(0.000)^{* * *}\end{array}$ & $\begin{array}{c}\mathbf{0 . 5 4 9 0} \\
(0.006)^{* * *}\end{array}$ \\
\hline vcrime & $\begin{array}{c}-\mathbf{0 . 0 9 6 0} \\
(0.000)^{* * *}\end{array}$ & $\begin{array}{c}-\mathbf{0 . 5 3 6 0} \\
(0.000)^{* * * *}\end{array}$ & $\begin{array}{c}-\mathbf{1 . 0 7 7 0} \\
(0.000)^{* * *}\end{array}$ & $\begin{array}{l}-\mathbf{0 . 8 9 3 0} \\
-0.239\end{array}$ \\
\hline crresid & & $\begin{array}{l}\mathbf{0 . 4 4 6 0} \\
(0.000)^{* * *}\end{array}$ & $\begin{array}{l}\mathbf{1 . 0 1 7 0} \\
(0.000)^{* * *}\end{array}$ & $\begin{array}{l}\mathbf{0 . 8 0 2 0} \\
-0.286\end{array}$ \\
\hline els & & & $\begin{array}{l}\mathbf{0 . 1 0 0 0} \\
(0.000)^{* * *}\end{array}$ & \\
\hline vcrimel1 (1 year lag) & & & $\begin{array}{l}-\mathbf{1 . 4 7 1 0} \\
(10.77)^{* * * *}\end{array}$ & $\begin{array}{l}-1.8190 \\
-1.67\end{array}$ \\
\hline vcrimel2 ( 2 year lag) & & & $\begin{array}{r}\mathbf{1 . 8 5 5 0} \\
(15.52)^{* * * *}\end{array}$ & $\begin{array}{l}1.6760 \\
-1.47\end{array}$ \\
\hline Control for gini & No & No & No & Yes \\
\hline Control for GDP growth rate & No & No & No & Yes \\
\hline Control for lagged GDP growth rates & No & No & No & Yes \\
\hline $\begin{array}{l}* * \text { significant at } 5 \% \text {; }{ }^{* * *} \text { significant at } 1 \% \text {. } \\
\text { Notes: Absolute value of z statistics in par } \\
\text { Source: Carol Graham and Soumya Chatto }\end{array}$ & $\begin{array}{l}\text { neses. } \\
\text { hhyay, using dat }\end{array}$ & n Latinoba & & \\
\hline
\end{tabular}


Table 5. Costs of Crime Victimization in Africa: Regressions of Living Conditions on Crime in Africa

\begin{tabular}{|c|c|c|c|c|c|c|}
\hline & \multicolumn{6}{|c|}{ Dependent variable: Living conditions } \\
\hline & \multicolumn{3}{|c|}{$\begin{array}{l}\text { For observations where personal security } \\
\qquad \geq 3\end{array}$} & \multicolumn{3}{|c|}{$\begin{array}{l}\text { For observations where personal } \\
\text { security }<3\end{array}$} \\
\hline & Coefficient & Stat sig. & $t$-score & Coefficient & Stat sig. & $t$-score \\
\hline Age & -0.0442 & $* * *$ & -7.34 & -0.037 & *** & -3.71 \\
\hline Age2 & 0.0003 & $* * *$ & 5.75 & 0.0003 & $* * *$ & 3.08 \\
\hline Years of education & 0.0822 & $* * *$ & 8.06 & 0.0854 & $* * *$ & 4.79 \\
\hline Gender: Male & -0.0833 & $* *$ & -2.46 & -0.1164 & $* *$ & -2 \\
\hline Income & 0.0794 & $* * *$ & 11.24 & 0.0787 & $* * *$ & 6.41 \\
\hline Urban & -0.0098 & & -0.25 & 0.2278 & $* * *$ & 3.2 \\
\hline Unemployed & -0.03 & & -0.75 & -0.0363 & & -0.53 \\
\hline Frequent Crime Victim & -0.0794 & $* * *$ & -4.08 & -0.0459 & $* *$ & -2.43 \\
\hline \multicolumn{7}{|l|}{ Country Dummies } \\
\hline Cape Verde & 0.3267 & **** & 4.58 & 0.0999 & *** & 0.64 \\
\hline Lesotho & -0.8754 & $* * *$ & -10.77 & -1.2125 & $* * *$ & -9.92 \\
\hline Mali & -0.1684 & $* * *$ & -2.16 & -0.2251 & & -1.21 \\
\hline Mozambique & 0.8037 & $* * *$ & 10.22 & 0.3064 & $* *$ & 2.39 \\
\hline South Africa & -0.0534 & & -0.76 & -0.2786 & $* *$ & -2.45 \\
\hline Kenya & 0.3875 & $* * *$ & 5.61 & 0.5895 & $* * *$ & 5.46 \\
\hline Malawi & -1.1061 & $* * *$ & -13.71 & -0.3532 & & -1.43 \\
\hline Namibia & 0.863 & $* * *$ & 11.02 & 0.8255 & $* * *$ & 5.89 \\
\hline Nigeria & 1.031 & $* * *$ & 15.86 & 0.7854 & $* * *$ & 5.82 \\
\hline Tanzania & -0.1136 & & -1.36 & 0.2647 & $* *$ & 2.14 \\
\hline Observations & 11675 & & & 3954 & & \\
\hline $\mathrm{LR}_{\mathrm{Chi}}{ }^{2}$ & 1880.57 & & & 605.18 & & \\
\hline
\end{tabular}

* Significant at $10 \%$ level; ** Significant at 5\% level; *** Significant at $10 \%$ level.

Notes: Uganda is a control country dummy.

Source: Carol Graham and Matthew Hoover, using data from www.afrobarometer.org

crime in an area where it is the norm are less likely to feel or suffer stigma effects than are those who are victims of crime in an area where it is rare. Or perhaps the negative effects of being a crime victim are mediated by the higher levels of optimism that we find among the poor and more precariously situated. All three explanations could be at play.

Chattopadhyay and I repeated our econometric analysis of crime with identical regressions and the pooled data, but with corruption victimization as the dependent variable. Like the crime question, the first order question was "Were you or someone in your family a victim of corruption in the past year?" We generated a similar corruption norm variable, based on the unobserved probability of being a corruption victim - as in the case of crime-and tested the extent to which it mediated the effects of corruption victimization on happiness. 
We get virtually identical results. Being a victim of corruption in the past year is correlated with lower happiness levels. Our corruption norm variable, on the other hand, is positively correlated with happiness (table 6). As in the case of crime, being a victim of corruption is mitigated in contexts where corruption is more common, and there are both less stigma effects and individuals have

Table 6. Effects of Corruption on Happiness in Latin America, Dependent Variable: Happiness

\begin{tabular}{|c|c|c|c|c|}
\hline \multirow{2}{*}{$\begin{array}{l}\text { Explanatory variables } \\
\text { age }\end{array}$} & \multirow{3}{*}{$\begin{array}{c}\text { Base specification } \\
\mathbf{- 0 . 0 2 3 0} \\
(0.000)^{* * *}\end{array}$} & \multicolumn{3}{|c|}{ With corruption residuals } \\
\hline & & -0.0210 & -0.0230 & -0.0190 \\
\hline & & $(0.000)^{* * *}$ & $(0.000)^{* * *}$ & $(0.003)^{* * *}$ \\
\hline \multirow[t]{2}{*}{ age 2} & 0.0000 & 0.0000 & 0.0000 & 0.0000 \\
\hline & $(0.000)^{* * *}$ & $(0.000)^{* * *}$ & $(0.000)^{* * *}$ & $(0.035)^{* *}$ \\
\hline \multirow[t]{2}{*}{ gender } & 0.0100 & 0.0410 & 0.0500 & 0.0470 \\
\hline & -0.473 & $(0.014)^{* *}$ & $(0.014)^{* *}$ & -0.075 \\
\hline \multirow[t]{2}{*}{ married } & 0.0840 & 0.0620 & 0.0710 & 0.0690 \\
\hline & $(0.000)^{* * *}$ & $(0.001)^{* * *}$ & $(0.001)^{* * *}$ & $(0.030)^{* *}$ \\
\hline \multirow[t]{2}{*}{ edu } & -0.0240 & -0.0350 & -0.0400 & -0.0380 \\
\hline & $(0.000)^{* * *}$ & $(0.000)^{* * *}$ & $(0.000)^{* * *}$ & -0.129 \\
\hline \multirow[t]{2}{*}{ edu 2} & 0.0010 & 0.0010 & 0.0010 & 0.0020 \\
\hline & -0.053 & $(0.002)^{* * *}$ & $(0.006)^{* * *}$ & -0.263 \\
\hline \multirow[t]{2}{*}{ socecon } & 0.2120 & 0.2270 & 0.2360 & 0.2400 \\
\hline & $(0.000)^{* * *}$ & $(0.000)^{* * *}$ & $(0.000)^{* * *}$ & $(0.000)^{* * *}$ \\
\hline \multirow[t]{2}{*}{ subinc } & 0.2910 & 0.3150 & 0.3120 & 0.3280 \\
\hline & $(0.000)^{* * *}$ & $(0.000)^{* * *}$ & $(0.000)^{* * *}$ & $(0.000)^{* * *}$ \\
\hline \multirow[t]{2}{*}{ ceconcur } & 0.2170 & 0.1840 & 0.2310 & 0.2120 \\
\hline & $(0.000)^{* * *}$ & $(0.000)^{* * *}$ & $(0.000)^{* * *}$ & $(0.000)^{* * *}$ \\
\hline \multirow[t]{2}{*}{ unemp } & -0.1680 & -0.2000 & -0.1890 & -0.2190 \\
\hline & $(0.000)^{* * *}$ & $(0.000)^{* * *}$ & $(0.000)^{* * *}$ & $(0.001)^{* * *}$ \\
\hline \multirow[t]{2}{*}{ poum } & 0.1760 & 0.1580 & 0.1690 & 0.1730 \\
\hline & $(0.000)^{* * *}$ & $(0.000)^{* * *}$ & $(0.000)^{* * *}$ & $(0.000)^{* * *}$ \\
\hline \multirow[t]{2}{*}{ domlang } & 0.5970 & 0.6680 & 0.6450 & 0.5880 \\
\hline & $(0.000)^{* * *}$ & $(0.000)^{* * *}$ & $(0.000)^{* * *}$ & $(0.001)^{* * *}$ \\
\hline \multirow[t]{2}{*}{ vcorr } & -0.1570 & -0.9160 & -0.9070 & -1.1420 \\
\hline & $(0.000)^{* * *}$ & $(0.000)^{* * *}$ & $(0.000)^{* * *}$ & $(0.017)^{* *}$ \\
\hline \multirow[t]{2}{*}{ corrresid } & & 0.8090 & 0.8330 & 1.0340 \\
\hline & & $(0.000)^{* * * *}$ & $(0.000)^{* * *}$ & $(0.027)^{* *}$ \\
\hline \multirow[t]{2}{*}{ els } & & & 0.0970 & \\
\hline & & & $(0.000)^{* * *}$ & \\
\hline Control for gini & No & No & No & Yes \\
\hline Control for GDP growth rate & No & No & No & Yes \\
\hline Control for lagged GDP growth rates & No & No & No & Yes \\
\hline
\end{tabular}

** significant at 5\%; *** significant at $1 \%$.

Notes: Absolute value of $\mathrm{z}$ statistics in parentheses.

Source: Carol Graham and Soumya Chattopadhyay, using data from Latinobarometro. 
adapted or become accustomed to it. Again, as in the case of crime, this adaptation is likely a good coping mechanism from an individual welfare perspective, but it also allows societies to remain in high corruption equilibriums for prolonged periods of time.

Our findings on the effects of both crime and corruption in Afghanistan support the adaptation hypothesis. Neither crime nor victimization due to corruption have significant effects on people's reported well-being in that country, perhaps because people are used to both (table 7) (Graham and Chattopadhyay 2009). Rather interestingly, there seem to be different crime and corruption norms in a few particular areas, which are characterized by more Taliban influence than the average. While our team was not able to interview in the conflict ridden zones, they did interview in a few districts in the south, characterized by more Taliban presence than the average. In these areas, which were happier, on average, than the rest of the sample, crime and corruption rates were lower (particularly the latter), and victims of corruption were significantly less happy than the average. The findings suggest that where norms differ-and thus attitudes about the phenomena differ-individuals are less likely to adapt to these phenomena and suffer greater well-being effects. And while our findings may have nothing to do with the Taliban, as there are many other unobservable differences across countries, they are surely suggestive of different norms of crime and corruption across them.

There are several ways to read these findings, as well as to judge whether adaptation is a good or bad thing for human welfare. Lower well-being costs are likely to make individuals more tolerant of or adaptable to such events, and thus less likely to do anything about them. At the same time, departing from a high crime or corruption norm is very hard-and potentially very costly-at the individual level. In other words, operating honestly in a situation where no one else does is inefficient and time consuming in the best instance and dangerous or risky in the worst. ${ }^{20}$ Thus rather than operate "irrationally" or in a costly manner, most individuals adapt to the higher crime norm. While that may be good for individual well-being - and perhaps survival - it may be negative in a collective sense, as it allows societies to fall into and stay in very bad equilibrium-such as the prolongation of very corrupt, violent regimes-for prolonged periods of time. These adaptation dynamics help explain why regimes such as Mobutu in Zaire or Fujimori in Peru were able to stay in power much longer than the predictions of most reasoned observers.

Tipping high crime and corruption equilibrium is difficult at best, although it surely is possible, as evidenced by the highly visible case of Medellin, Colombia. Medellin had the highest murder rate - or at least one of the highest, accepting that these things are difficult to measure precisely-in the world in the early part of the millennium. After that, its crime rate tipped downward dramatically, due to 


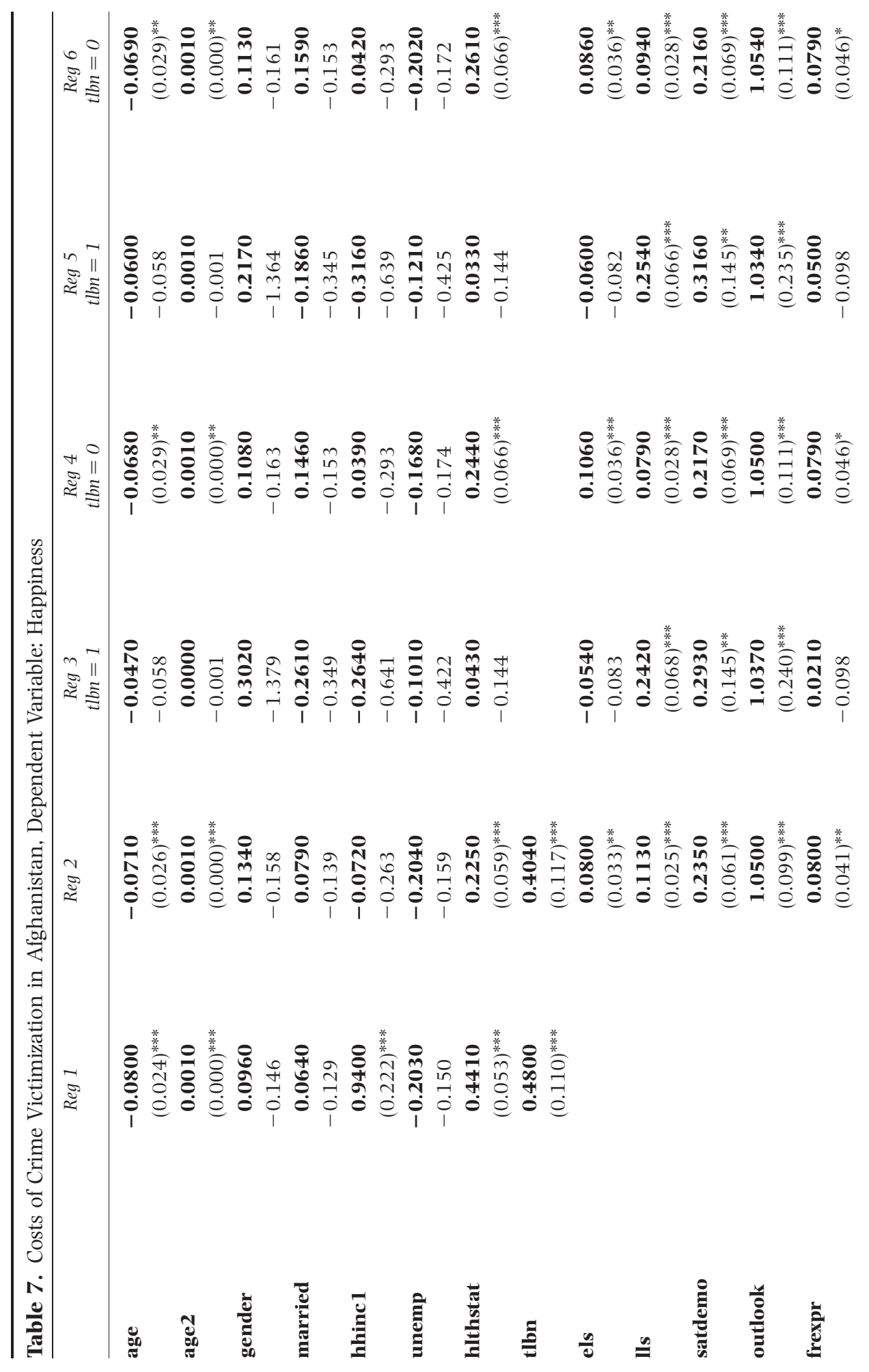




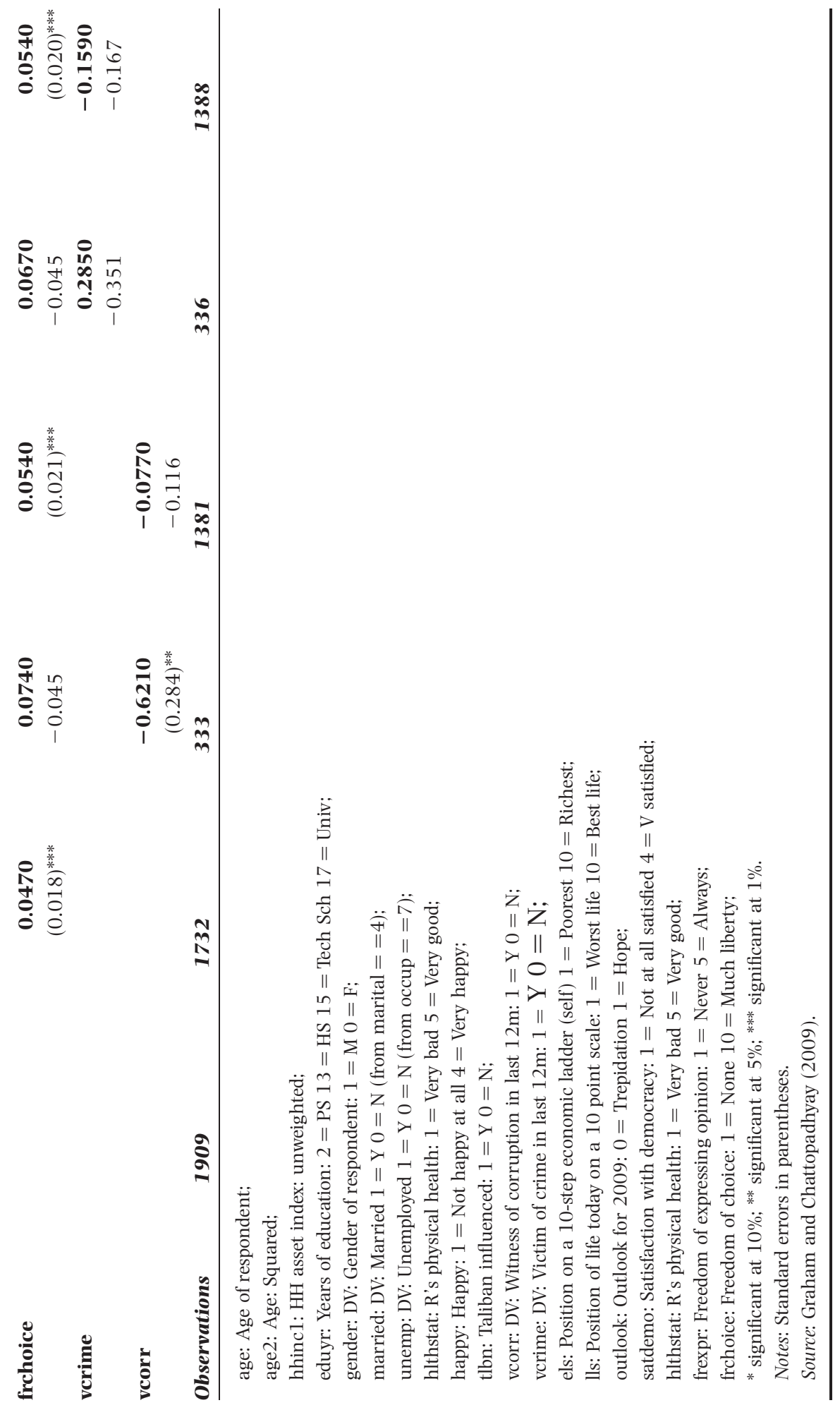


a number of critical factors, including the leadership of a dynamic mayor, as well as crime rates reaching intolerable levels (the definition of tolerance obviously varies across populations). By 2008, citizens in Medellin had more confidence in their police than in any other city in the country, by a wide margin: 80 percent of respondents rather than 50 percent in other cities (see Encuesta Annual Ciudadana Sobre Percepcion y Victimizacion).

In the same way that individuals adapt to the benefits (and also to the negative externalities) of overall rising income trends, they also adapt to the costs of rising crime and corruption trends. In the same way that income increases across time may not result in commensurate increases in well-being: increasing crime and corruption may not result in commensurate decreases in well-being as societies adapt to these phenomena. $^{21}$ There are surely tipping points in both instances, as levels of crime and corruption become unsustainable (for example), as rising income levels result in positive externalities that increase happiness, or both (as well as, perhaps, greed).

\section{Adapting to Illness: Variance in Health Norms across Cohorts and Countries}

The health arena provides another example of adaptation. A great deal of the variance in reported health satisfaction cannot be explained by objective differences, and my research — with several colleagues — finds a major role for adaptation and variance in norms of health. A telling example is that while objective health indicators are better in the Netherlands than in the United States, reports of workrelated disability are higher in the former than in the latter (Kapteyn, Smith, and van Soest 2007). Reports of conditions like diabetes and hypertension, meanwhile, are notoriously inaccurate, particularly in poor countries where awareness of these conditions is low. Across all countries, they are mediated by income and education, among other factors. ${ }^{22}$

Across countries, there is higher tolerance for poor health in the poorer countries, and less satisfaction with better health in the rich ones. Within countries, while rich people are slightly more satisfied with their health than poor ones, and more "objective" measures of health, such as the EQ5D health index, also track with socioeconomic status, the gaps in the assessments of satisfaction are much smaller than the gaps in objective conditions (quality, access, outcomes) would predict. $^{23}$ The same often holds across education, job, and economic satisfaction domains, depending on the sample. ${ }^{24}$

Lora and collaborators, and Chattopadhyay and I, (using different datasets for Latin America) find that respondents in poor countries are more or at least as likely to be satisfied with their health systems than are respondents in wealthier ones, while respondents in some very poor countries, such as Guatemala, have 
much higher levels of health satisfaction than do those in much wealthier ones with better health systems, such as Chile. Deaton finds the same pattern-or lack of one-with satisfaction with health systems in the worldwide Gallup Poll. The same percentage of Kenyans (82 percent) are satisfied with their health system as are citizens of the United States. While there are surely outliers, objective health conditions - as measured by indicators such as morbidity and life expectancyare materially better in the wealthier countries (Deaton 2008; Graham and Lora 2009; Graham and Chattopadhyay 2009).

Cross-country comparisons of average levels of personal health satisfaction demonstrate a similar, although not as notable, pattern. Health satisfaction seems to be more closely associated with cultural differences across countries than it is with objective indicators, such as life expectancy and infant mortality, or with per capita incomes.

Within countries, wealthier respondents are more likely to be happier and more satisfied with their health than are poor ones. Despite the aggregate pattern, though, there is clearly an "optimism bias" in the responses of the poorest respondents, in health as well as in other domains, at least in Latin America. The gaps between the subjective assessments of the rich and poor are much smaller than the gaps in objective indicators.

As a means to study the role of differential norms, Andrew Felton and we explored the effects of obesity on well-being in the United States and Russia, based on the National Longitudinal Survey of Youth (NLSY; www.bls.gov/nls/nlsy79 .htm) for the former and the Russian Longitudinal Monitoring Survey (RLMS; www.cpc.unc.edu/projects/rlms) for the latter. For the United States, we found that in cohorts where obesity rates are high, such as among blacks and Hispanics, obese people do not report being more unhappy than others, whereas in cohorts where obesity rates are low, obese people tend to be much less happy (controlling for other factors such as age, gender, and income) (Graham 2008b). Thus it makes one less unhappy to be obese if high levels of obesity are the norm (figure 2). There is also a negative link between obesity and upward income mobility, suggesting that poor health norms may be poverty traps as well as health traps. In Russia, where obesity is still seen as a sign of prosperity, we found that obese respondents, who were typically wealthy businessmen or farmers, were happier, on average, than others, again suggesting an important mediating role for norms of health. These findings were above and beyond the objective health effects of obesity - such as propensity for diabetes, high blood pressure, and heart disease.

In other research, based on the Gallup World Poll for Latin America, we find that the (expected) negative effects of extreme conditions in self-care and mobility (as measured by the EQ5D index) on both life satisfaction and health satisfaction disappear when a control for personal optimism is included (Graham and Lora, 2009). It is likely that people adapt to these conditions, and the importance of 
Figure 2. Obesity and Unhappiness: United States

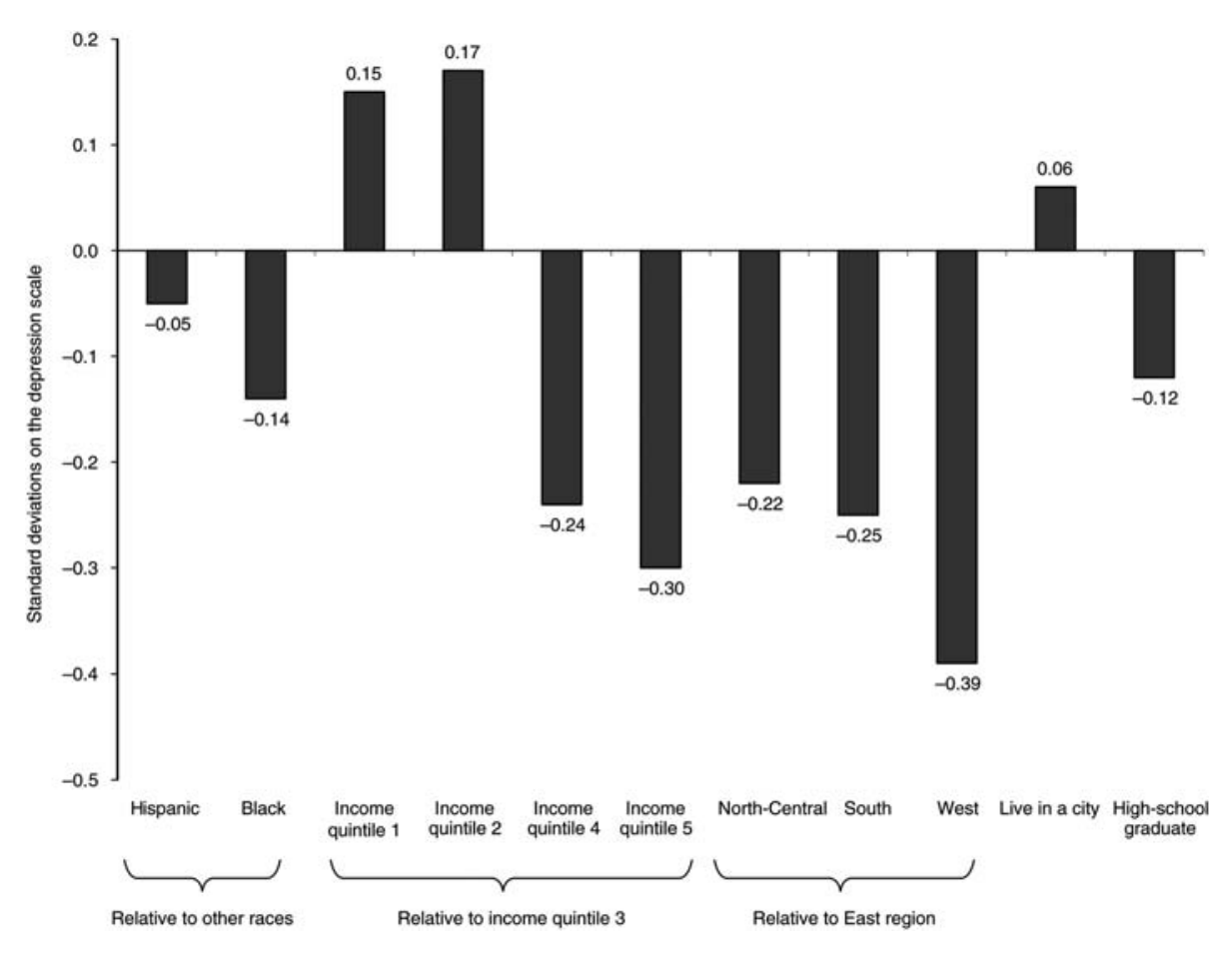

Source: Graham (2008).

inherent character traits in maintaining happiness or satisfaction is more important than (irreversible) objective conditions. In contrast, extreme pain, extreme anxiety, and the usual activities continue to have negative effects on health satisfaction when the optimism control is included, suggesting that even naturally optimistic people cannot adapt to these conditions (figure 3).

It is likely that people are less able to adapt to the unpredictability of certain health conditions than they are to the unpleasant certainty of others. The wellbeing of paraplegics, for example, typically adapts back, while many epileptics face a lifetime of uncertainty about when they will have seizures. A number of studies of the quality of life of epileptics find that age - and in particular higher age of onsetposed significant and negative effects on health-related quality of life. Adapting to the uncertainty is probably more difficult later in life, when social, economic, and psychological dimensions are more established (Lua and others 2007).

Andy Eggers, Sandip Sukhtankar, and I find that innate optimism mediates the intensity of the effects of anxiety, such as fear of unemployment, on well-being in Russia (Graham, Eggers, and Sukhtankar 2004). Optimism likely interacts with the anxieties related to particular conditions to determine health satisfaction. 
Figure 3. Income Equivalences of Health Conditions in EQ5D

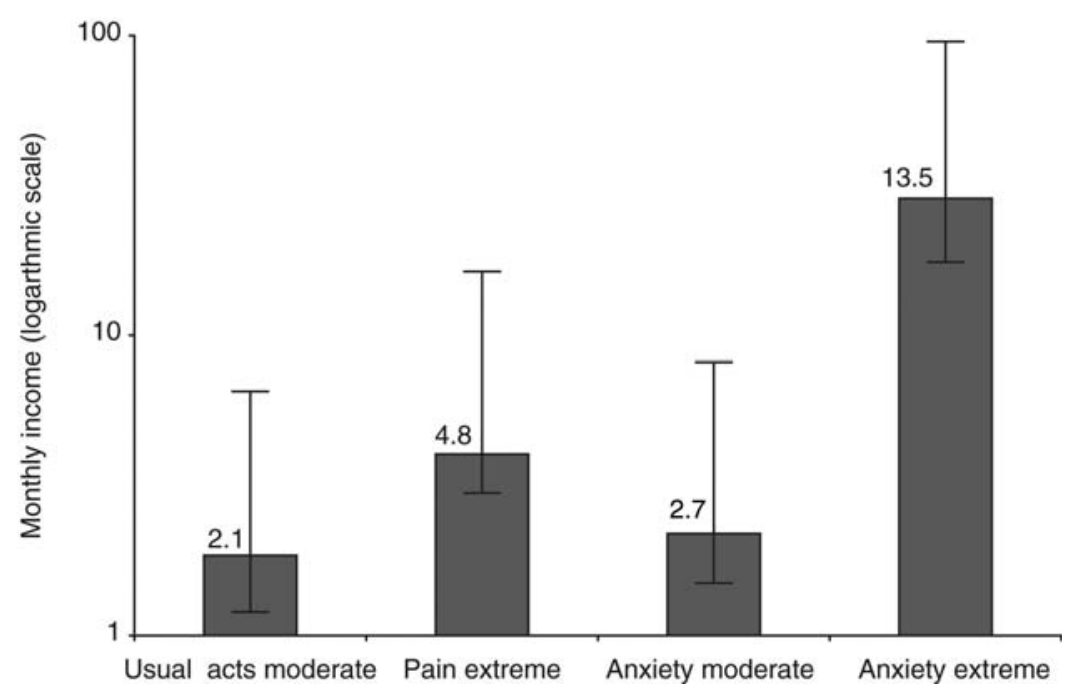

Notes: Direct equivalences are based on the effect of each health component on life satisfaction. The EQ5D equivalences are based on the effect of changes in the EQ5D index, derived from changes in each health component. Vertical bars represent a 95 percent confidence interval.

Source: Authors' calculations based on Gallup World Poll 2006 and 2007.

Finally different levels of tolerance for disease and pain, which can vary significantly across countries and cultures, also mediate the relationship between objective and subjective health conditions.

All of these findings help explain why norms of health vary so much across countries, cohorts, and cultures, and why quality of health care varies so much even across countries with comparable levels of GDP. Demand for better health care is often lower in societies that need improvements much more than it is in those that have much better care, but they also have very different norms of health and higher aspirations based on those norms. And once again, individuals' capacity to adapt to adversity - in this case ill health-yet maintain relatively high happiness levels, may be a good protective mechanism from an individual psychological perspective, but at the same time may yield collective tolerance for poor health systems and health status.

\section{Conclusions and Implications for Policy}

Understanding what makes people happy and why may help us understand some of the fundamental questions in economics, such as the relationships between 
happiness and income and happiness and health, as well as how these relationships differ in different countries and in different cultures at different stages of development. What makes people happy seems to be remarkably similar in all sorts of countries and contexts, from war torn Afghanistan to new democracies like Chile and established ones like the United Kingdom.

Increasing levels of income-and income growth-tend to be accompanied by rising expectations and related frustrations (at the macrolevel, the paradox of unhappy growth; and at the microlevel, the frustrated achievers), across a surprisingly wide range of countries at different economic development levels. At the same time, individuals across the globe seem remarkably skilled at adapting expectations downwards when necessary-our so-called happy peasants. In the same way that rising incomes do not translate into ever increasing levels of happiness, remarkably adverse circumstances, such as high levels of crime and corruption or very poor standards of health, do not seem to result in equivalently low levels of happiness. Happiness levels vary across countries and with economic and institutional conditions. Yet there is evidence of a great deal of upward and downward adaptation, as well as a clear role for innate character traits, in mediating the relationship between happiness and a range of environmental variables.

Surely deep deprivation makes people unhappy, while many things that accompany higher levels of development, such as better public goods and less disease, make people happier. Yet higher per capita income levels do not translate directly into higher average happiness levels. In part this is because there are major differences in the nature of public goods and institutional regimes across countries. There are also cultural differences in people's concepts of happiness, which are even more difficult to measure.

Adapting expectations downward in difficult contexts or at times of adversity, such as economic crises or rising rates of crime, seems to be a useful trait for preserving individual happiness in the face of major challenges. At the same time, it may result in lower levels of aggregate welfare if it translates into societal tolerance for bad equilibrium, such as high levels of crime and corruption or dysfunctional governments. Rising expectations in the context of economic progress or major improvements in health, in contrast, may actually reduce happiness, or at least require constantly increasing incomes or health improvements to keep well-being levels constant. At the same time rising expectations may generate demand for better standards in areas such as health and education. Individual ability to adapt, meanwhile, is determined by some intersect between innate character traits (being naturally cheerful or curmudgeonly, for example) and experience in the environment. At minimum, these insights allow us to understand better how societies can be surprisingly tolerant-and happy - in the context of very bad conditions, and surprisingly critical—and unhappy—in the context of good conditions. 
The obvious question, then, is how relevant is all of this for policy? What can policymakers take from these lessons? Can nations develop progress indicators based on the findings from happiness surveys? There is increasing discussion of using happiness surveys as a tool for public policy, such as national well-being accounts, as complements to national income accounts, most recently supported by the Sarkozy Commission (Diener and Seligman 2004; Kahneman and others 2004).

Yet there are still unanswered questions, not least the relevant definition of "happiness." What makes it a useful survey instrument is its open-ended nature, and the definition is left to the respondent, allowing us to compare happiness responses across individuals in a wide range of countries and cultures. Yet the definition of happiness matters to its application for policy, which then raises a host of normative questions. Is happiness merely contentment? Is it contentment, welfare, and dignity? Is it something else? Different societies would surely come to different conclusions about what was worth pursuing as a policy objective, but at this point we lack an analytical frame for posing such a question to the general public.

People in Afghanistan live in dire poverty and in a context of continuous violence, yet are happier than people in Chile. What can we do with this information? At minimum it is a window into human psychology which can help explain how Afghan and Chilean societies can coexist as distinct equilibria, even in a world where global information and transportation have eroded all sorts of boundaries and borders. Understanding how to make Afghanistan's social equilibrium closer to Chile's-at least in terms of freedom, citizen trust, health, and security-is a challenge that our findings pose but cannot resolve.

These issues are related to two broader questions in economics that this paper speaks to, but only implicitly: incomparable standards of welfare and endogenous preferences. While happiness surveys cannot overcome the challenges raised by these questions, they can give us information about their patterns and variance across countries and cohorts, patterns that we cannot infer from revealed preferences. The question of the appropriate definition of happiness speaks to different standards of welfare, while the issue of adaptation in part reflects endogenous preferences. Happiness surveys allow us to see how and if patterns in endogenous preferences vary across cohorts or across domains, such as health or security. They also allow us to explore further the question of why people in different contexts seem to have different standards of welfare, in part due to conditions that they have no control over, but in part due to cultural and other differences.

The challenge that remains is the translating of the results into metrics that are useful for development economists and practitioners. Because individuals can adapt to extreme adversity and remain happy does not mean that their needs are less compelling than the needs of those who live in conditions of greater 
prosperity, with higher aspirations of welfare, freedom, and health, among other things. This obviously poses a challenge to making cross-country welfare comparisons based on the results of happiness surveys.

At the same time, the surveys provide information that complements income data and give us a broader base of information upon which to base policy decisions. Understanding that individuals can adapt to adversity and to poor norms of health, crime, and governance can help to explain puzzling differences in the demand for public services across countries and cohorts, for example. Understanding that, on average, adapting to unpleasant certainty is easier than adapting to less unpleasant uncertainty can help explain opposition to policy reforms in contexts which seem intolerable and in dire need of change by most external assessments. And some policies, such as those designed to increase demand for health services or generate support for measures to combat crime and corruption, may result in marked increases in unhappiness before they achieve their desired objectives, due to raised awareness or heightened expectations. Directly testing whether there is, indeed, a negative correlation between happiness and the pressure to change policies is an important subject for future research.

The "science" of happiness is a nascent one. The insights that we are gaining in studying it around the world are helping to advance it by deepening our understanding of the complex interchange between the psychological and contextual determinants of human well-being across a wide range of development levels. Yet this does not answer the question whether happiness should be a policy objective going forward. The results - and in particular the role of adaptation in explaining conundrums in those results-suggest that any move in this direction needs to be a cautious one which addresses differences in norms and expectations across societies on the one hand, and the need for a modicum of consensus on the definition of happiness on the other.

\section{Notes}

Carol Graham is Senior Fellow and Charles Robinson Chair at the Brookings Institution and College Park Professor at the University of Maryland; email address: cgraham@brookings.edu. The author would like to thank the participants in seminars at the Legatum Institute in London and at the Millennium Challenge Corporation for their helpful reactions, as well as Bruno Frey, Sabina Alkatire, Emmanuel Jimenez, and three anonymous reviewers for more detailed comments.

1. For a summary of the many scholars and range of topics involved, see the chapter on happiness economics by Graham (2008a).

2. The correlation coefficient between the two ranges between .56 and .50, based on research on British data for 1975-92, which includes both questions, and Latin American data for 200001, in which alternative phrasing was used in different years (Blanchflower and Oswald 2004; Graham and Pettinato 2002).

3. Microeconometric happiness equations have the standard form: $W_{i t}=\alpha+\beta x_{i t}+\epsilon_{i t}$, where $W$ is the reported well-being of individual $i$ at time $t$, and $X$ is a vector of known variables including 
sociodemographic and socioeconomic characteristics. Unobserved characteristics and measurement errors are captured in the error term.

4. The coefficients produced from ordered probit or logistic regressions are remarkably similar to those from OLS regressions based on the same equations, allowing us to substitute OLS equations for ordered logit or probit and then attach relative weights to them. For an extensive and excellent discussion of the methodology underpinning happiness studies - and how it is evolving - (see Van Praag and Ferrer-i-Carbonell 2004).

5. A number of scholars, such as Deaton (2008) and Stevenson and Wolfers (2008), have demonstrated a clear relationship between per capita incomes and average happiness levels, with no sign that the correlation weakens, either as income levels increase or over time. This is with a loglinear specification.

6. For detail on this debate, see Graham, Chattopadhyay, and Picon (2010).

7. The behavioral economics literature, meanwhile, shows that individuals value losses more than gains. Easterlin argues that individuals adapt more in the income or financial arenas than in non-income related arenas, while life changing events, such as bereavement, have lasting effects on happiness (Kahneman, Diener, and Schwarz 1999).

8. See Lora and Chaparro (2009). See also Deaton (2008) and Stevenson and Wolfers (2008). It is also possible that initially happier countries grew faster than initially unhappy countries with the same income (perhaps because they had happier, more productive workers) and thus the coefficient on growth in a regression which compares the two with final income and final happiness is negative. I thank Charles Kenny for raising this point.

9. Javier Herrera, for example, using panel data for Peru and Madagascar, finds that people's expectations adapt upwards during periods of high growth and downwards during recessions, and that this adaptation is reflected in their assessments of their life satisfaction. People are less likely to be satisfied with the status quo when expectations are adapting upwards. Recent work on China by Whyte and Hun (2006) confirms the direction of these findings.

10. A related body of research examines the effects of inequality and relative income differences on well-being, and how inequality mediates the happiness-income relationship. At some level, individuals probably adapt to inequality as they do to other things (and are less good at adapting to changes in inequality). I do not cover the topic here; it merits an entire paper on its own. For more detail, see Graham and Felton (2006) and Luttmer (2005).

11. For more detail on the welfare effects of the U.S. 2009 crisis and on the method, see Graham and Chattopadhyay (2008a, 2008b) and Graham, Chattopadhyay, and Picon (2009). For work on earlier crises, see Graham and Sukhtankar (2004) and Eggers, Gaddy, and Graham (2006).

12. For a comprehensive review, including of Putnam's work, see Grootaert and van Bastelaer (2002).

13. The question in the Gallup Poll is phrased thus: "If you were in trouble, do you have friends or relatives you can count on, or not?"

14. Andrew Clark and Orsolya Lelkes explore the issue of religion in greater detail and attempt to tease out the differences between belonging to a religion and having faith on the one hand, and the positive externalities that come from the related social networks on the other. They look across 90,000 individuals across 26 European countries and find that, not surprisingly, reporting to belong to a religion is positively correlated with life satisfaction. More surprising, though, they find that average religiosity in the region also has a positive impact: people are more satisfied in more religious regions, regardless of whether they themselves are religious or non-believers ("atheists"). See Clark and Lelkes (2009).

15. They drop eight countries which do not have specifications for income. See Helliwell, Haifang Huang, and Harris (2008).

16. Rather interestingly, the same respondents scored well below the world average on a best possible life question, suggesting that they are well aware of how their lives compare in relative terms to those elsewhere. For detail see Graham and Chattopadhyay (2009).

17. Regression results are reported in Graham and Pettinato (2002). 
18. Graham and Chattopadhyay (2008) and Powdthavee (2005). For an overview of the interaction between behavior and institutions and the evolution of norms, see Bowles (2004) and Young (1998).

19. Our basic econometric strategy was as follows. Our first stage regression had the probability of being a crime victim (a logit equation, based on a yes-no crime victim question) as the dependent variable. We then used a vector of controls for personal and socioeconomic characteristics (including being unemployed or a minority or not) along with other factors that could explain crime victimization: the reported crime rate, lagged growth, the Gini coefficient, lagged crime victimization (individual crime victimization both one and two years ago), and controls for the size of the city respondents live in (small, medium, or large, with the idea that there is more crime in large cities), plus the usual error term. We isolated the resulting residuals (error terms) as each individual's unexplained crime probability, for example the probability of being victimized that was not explained by objective traits. We then included that residual as an independent variable in a second stage regression with happiness on the left-hand side and the usual sociodemographic controls (including minority status) plus crime victimization on the right-hand side.

20. Francisco Thoumi (1987) has written eloquently about the costs of diverting from corrupt practices, such as refusing to pay a bribe, where corruption is the norm.

21. For a discussion of how people adapt and how these strategies may vary across socioeconomic cohorts, see DiTella, Galiani, and Shargrodsky (2007).

22. Thomas and Frankenburg (2000) first studied differences in self-reported and measured health, based on the Indonesian Family Life Survey. Susan Parker and her colleagues built on that work and studied these differences based on a broad purpose, multitopic, nationally representative survey in Mexico, first conducted in 2002 and then repeated in 2005. Income predicts lower differences between measured and reported height, while the probability of having seen a doctor in the past three months increases the probability of accurately reporting weight among the obese and overweight. Of her total sample, 7 percent do not have hypertension but think they do; and 13 percent have it but do not know it. See Parker, Rubalcava, and Teruel (2008).

23. The EQ5D is a five-part questionnaire developed for the British general population, and now widely used in other contexts. The descriptive dimensions are: mobility, self-care, usual activities, pain/discomfort, and anxiety/depression, with the possible answers for each being: no health problems, moderate health problems, and extreme health problems. See Shaw, Johnson, and Coons (2005).

24. Of course, this could also be considered a pessimism bias of the rich.

\section{References}

The word processed describes informally reproduced works that may not be commonly available through libraries.

Blanchflower, D., and A. Oswald. 2004. "Well-being Over Time in Britain and the USA.” Journal of Public Economics 88:1359-87.

Bowles, Samuel. 2004. Microeconomics: Behavior, Institutions, and Evolution. Princeton, NJ: Princeton University Press.

Clark, A., and O. Lelkes. 2009. "Let Us Pray: Religious Interactions in Life Satisfaction." Processed, Paris School of Economics, January.

Deaton, Angus. 2008. "Income, Health, and Well-Being Around the World: Evidence from the Gallup World Poll." Journal of Economic Perspectives 22(2): 53-72. 
Diener, Ed, and Martin Seligman. 2004. "Beyond Money: Toward an Economy of Well-being." Psychological Science in the Public Interest 5(1): 1-31.

Diener, E., E. Sandvik, L. Seidlitz, and M. Diener. 1993. "The Relationship between Income and Subjective Well-being: Relative or Absolute?" Social Indicators Research 28(3): 195-223.

DiTella, R., S. Galiani, and E. Shargrodsky. 2007. "Crime Distribution and Victim Behavior During a Crime Wave." Processed, Harvard University, November.

Easterlin, R. 2003. "Explaining Happiness." Proceedings of the National Academy of Sciences 100(19): 11176-83.

Eggers, Andrew, Clifford Gaddy, and Carol Graham. 2006. "Well-being and Unemployment in Russia in the 1990s: Can Society's Suffering Provide Individual Solace.” Journal of Socio-Economics 35(2): 209-42.

Frey, B., and A. Stutzer. 2002. Happiness and Economics. Princeton, NJ: Princeton University Press.

Graham, Carol. 2005. "Insights on Development from the Economics of Happiness.” World Bank Research Observer 20(2).

2008a. “The Economics of Happiness.” In Steven N. Durlauf, and Lawrence E. Blume, eds., The New Palgrave Dictionary of Economics, 2nd edn. Basingstoke, UK: Palgrave Macmillan.

2008b. "Happiness and Health: Lessons - and Questions - for Policy." Health Affairs, January-February.

2009. Happiness around the World: The Paradox of Happy Peasants and Miserable Millionaires. Oxford: Oxford University Press.

Graham, Carol, and Soumya Chattopadhyay. 2008a. "Public Opinion Trends in Latin America (and the US): How Strong is Support for Markets, Democracy, and Regional Integration?” Paper prepared for the Brookings Partnership for the Americas Commission, Washington, DC, June.

2008b. "Gross National Happiness and the Economy." The Globalist, October 24.

2009. "Well Being and Public Attitudes in Afghanistan: Some Insights from the Economics of Happiness." World Economic, Vol. 10, No. 3, July-September.

Graham, Carol, and Andrew Felton. 2006. "Does Inequality Matter to Individual Welfare: An Exploration Based on Happiness Surveys in Latin America." Journal of Economic Inequality 4: $107-22$.

Graham, Carol, and Eduardo Lora, eds. 2009. Paradox and Perception: Measuring Quality of Life in Latin America. Washington, DC.: The Brookings Institution Press.

Graham, Carol, and Stefano Pettinato. 2002. Happiness and Hardship: Opportunity and Insecurity in New Market Economies. Washington, DC: The Brookings Institution Press.

Graham, Carol, and Sandip Sukhtankar. 2004. "Does Economic Crisis Reduce Support for Markets and Democracy in Latin America? Some Evidence from Surveys of Public Opinion and Wellbeing." Journal of Latin American Studies 36:349-77.

Graham, Carol, Soumya Chattopadhyay, and Mario Picon. 2009. "Does the Dow Get You Down? Happiness and the U.S. Economic Crisis." Processed. The Brookings Institution.

. 2010. "The Easterlin Paradox Re-visited: Why Both Sides of the Debate May be Correct." In Ed Diener, John Helliwell, and Daniel Kahneman, eds., International Differences in Well-being. Oxford: Oxford University Press.

Graham, Carol, Andrew Eggers, and Sandip Sukhtankar. 2004. "Does Happiness Pay? An Initial Exploration Based on Panel Data for Russia." Journal of Economic Behavior and Organization 55(3): $319-42$.

Granovetter, M. 1973. "The Strength of Weak Ties.” American Journal of Sociology 78:1360-79. 
Grootaert, C., and T. van Bastelaer, eds. 2002. The Role of Social Capital in Development: An Empirical Assessment. Cambridge: Cambridge University Press.

Helliwell, J., H. Haifang Huang, and A. Harris. 2008. "International Differences in the Determinants of Life Satisfaction." Processed. University of British Columbia.

Hudson, John. 2006. "Institutional Trust and Subjective well-Being Across the EU." Kyklos 59: $43-62$.

Inglehart, R., R. Foa, C. Peterson, and C. Welzel. 2008. "Development, Freedom, and Rising Happiness: A Global Perspective (1981-2007).” Perspectives on Psychological Science 3(4).

Inter-American Development Bank. (2008). Beyond Facts: Understanding Quality of Life in Latin America. Washington, DC: Inter-American Development Bank.

Kahneman, D., E. Diener, and N. Schwarz. 1999. Well-being: The Foundations of Hedonic Psychology. New York: Russell Sage.

Kahneman, D., A. Krueger, D. Schkade, N. Schwarz, and A. Stone. 2004. "Toward National Wellbeing Accounts." AEA Papers and Proceedings 94:429-34.

Kapteyn, Arie, James P. Smith, and Arthur van Soest. 2007. "Vignettes and Self-Reports of Work Disability in the United States and the Netherlands." American Economic Review 97(1): 461-73.

Knight, J., and R. Gunatilaka. 2007. "Great Expectations? The Subjective Well-being of Rural-Urban Migrants in China.” Discussion Paper Series 322, Department of Economics, University of Oxford, April.

Labonne, Julienne, and Robert Chase. 2008. "So You Want to Quit Smoking: Have You Tried a Mobile Phone?” World Bank Policy Research Working Paper Series 4657, Washington, DC: The World Bank, June.

Lora, Eduardo, and Juan Camilo Chaparro. 2009. "Satisfaction Beyond Income.” In Carol Graham, and Eduardo Lora, eds., Paradox and Perception: Measuring Quality of Life in Latin America. Washington, DC: The Brookings Institution Press.

Lua, Lin, Halilah Haron, Gertrude Cosmos, and Nurul Hudoni Nawi. 2007. "The Impact of Demographic Characteristics on Health-Related Quality of Life: Profile of Malaysian Epilepsy Population." Applied Research in Quality of Life 2.

Luttmer, E. 2005. "Neighbors as Negatives: Relative Earnings and Well-being." Quarterly Journal of Economics 120(3).

Oswald, A. 1997. "Happiness and Economic Performance." Economic Journal 107:1815-31.

Parker, Susan, Luis Rubalcava, and Graciela Teruel. 2008. "Health in Mexico: Perceptions, Knowledge and Obesity." Paper prepared for the Inter-American Development Bank Project on Understanding Quality of Life in LAC, January.

Powdthavee, Nicholas. 2005. "Unhappiness and Crime: Evidence from South Africa." Economica 72: $531-47$.

Shaw, James W., Jeffrey A. Johnson, and Stephen Joel Coons. 2005. "US Valuation of the EQ-5D Health States: Development and Testing of the D1 Valuation Model." Medical Care 43(3): 203-20.

Stevenson, Betsey, and Justin Wolfers. 2008. "Economic Growth and Subjective Well-Being: Re-assessing the Easterlin Paradox." Brookings Panel on Economic Activity, Spring.

Tella, R., and R. MacCulloch. 2006. "Happiness and Adaptation to Income and Status: Evidence from an Individual Panel." Processed, Harvard University.

Thomas, D., and E. Frankenburg. 2000. "The Measurement and Interpretation of Health in Social Surveys." In C.J.L. Murray and others, eds., Summary Measures of Population Health. Geneva: World Health Organization. 
Thoumi, E. 1987. "Some Implications of the Growth of the Underground Economy." Journal of InterAmerican Studies and World Affairs 29(2).

Van Praag, B., and A. Ferrer-i-Carbonell. 2004. Happiness Quantified: A Satisfaction Calculus Approach. Oxford: Oxford University Press.

Veenhovern, R. 2000. "Freedom and Happiness: A Comparative Study of 46 Nations in the Early 1990s." In Ed Diener, and E. Suh, eds., Culture and Subjective Well-being. Cambridge, MA: MIT Press.

Whyte, M., and C. Hun. 2006. "Subjective Well-being and Mobility Attitudes in China." Processed, Harvard University.

Wolf Shenk, Joshua. 2009. "What Makes Us Happier?" The Atlantic, June.

Young, Peyton. 1998. Individual Strategy and Social Structure: An Evolutionary Theory of Institutions. Princeton, NJ: Princeton University Press. 